\title{
Relationship between Upper Quarter Y Balance Test performance and throwing proficiency in adolescent Olympic handball players
}

Julian Bauer ${ }^{*}$ (D), Simon Schedler, Stephan Fischer and Thomas Muehlbauer

\begin{abstract}
Background: Olympic handball is a sport mainly focused on executing throwing and passing techniques with the throwing arm. Functional specialization due to the unilateral characteristic and dominance of the throwing arm may lead to adapted control of shoulder stability and mobility. Thus, we examined side differences between the throwing and the non-throwing arm. Additionally, correlations between the Upper Quarter Y Balance Test (YBT-UQ) and handball-specific performance measures were investigated.

Methods: All participants ( $F=13$ yrs., $n=14$, training experience [te] $5.9 \pm 1.3 \mathrm{yrs.;} M=14 \mathrm{yrs}$., $n=24$, te $6.5 \pm 2.5 \mathrm{yrs}$.; $M=15 \mathrm{yrs}$., $n=18$, te $9.3 \pm 2.2 \mathrm{yrs}$ ) were Olympic handball players of a regional youth selection team. YBT-UQ was executed assessing performance in medial, inferolateral and superolateral reach direction normalized to the upper limb length together with a composite score of the mean of all reach directions. A radar gun and a target net were used for the assessment of throwing velocity and throwing accuracy. The paired $t$-test was used to detect side differences in YBT-UQ performance. Pearson's correlation analysis was calculated for associations between YBT-UQ and throwing velocity/accuracy.

Results: Significant differences between the throwing and non-throwing arm were only detected for the superolateral reach direction in the 14-year-old males. Small correlations between YBT-UQ performance and throwing velocity/accuracy (13-year-old females: $-0.01 \leq r \leq-0.37 / 0.01 \leq r \leq 0.31$; 14 -year-old males: $0.10 \leq r \leq$ $0.45 /-0.01 \leq r \leq .-0.51 ; 15$-year-old males: $0.06 \leq r \leq 0.34 / 0.01 \leq r \leq-0.45$ ) were observed, irrespective of age and sex category.

Conclusions: There was only a minimal difference in performance of the YBT-UQ between the throwing and nonthrowing arm and only weak if any relationships between throwing performance and stability/mobility of the upper extremities in adolescent Olympic handball players existed. Further research is needed to investigate whether the YBT-UQ is a useful tool to detect training-related improvements in measures of shoulder stability/mobility and functional performance.
\end{abstract}

Keywords: Postural control, Upper quarter mobility/stability, Throwing velocity/accuracy, Young athletes

* Correspondence: julian.bauer@uni-due.de

Division of Movement and Training Sciences/Biomechanics of Sport,

University of Duisburg-Essen, Gladbecker Str. 182, 45141 Essen, Germany

(c) The Author(s). 2020 Open Access This article is licensed under a Creative Commons Attribution 4.0 International License, which permits use, sharing, adaptation, distribution and reproduction in any medium or format, as long as you give appropriate credit to the original author(s) and the source, provide a link to the Creative Commons licence, and indicate if changes were made. The images or other third party material in this article are included in the article's Creative Commons licence, unless indicated otherwise in a credit line to the material. If material is not included in the article's Creative Commons licence and your intended use is not permitted by statutory regulation or exceeds the permitted use, you will need to obtain permission directly from the copyright holder. To view a copy of this licence, visit http://creativecommons.org/licenses/by/4.0/ The Creative Commons Public Domain Dedication waiver (http://creativecommons.org/publicdomain/zero/1.0/) applies to the data made available in this article, unless otherwise stated in a credit line to the data. 


\section{Background}

Olympic handball is a fast-paced contact sport [1]. Contrary to soccer in which bilateral exercises are frequently used in systematic training [2], Olympic handball training is mainly focused on executing throwing and passing techniques with the throwing arm, with the athletes rarely varying the playing arm and hand. Therefore, the functional specialization due to the unilateral characteristic and dominance of the throwing arm may lead to adapted movement control [3, 4] following the regular and specific unilateral execution of Olympic handball training.

Throwing is a key factor in Olympic handball $[5,6]$ and a complex skill including motion technique [7], physical characteristics [8], and motor skills $[9,10]$ involving both mechanical and muscular aspects [11]. Throwing techniques can be divided into the standing throw, the standing throw with up to three steps run-up and the jump throw [11]. A proximal to distal sequential muscle activation $[12,13]$ and the need for an effective energy transfer [14] is present in all these types of throws. Beside the different throwing techniques, optimal scapula control [15] and the need for thoracic mobility [16] seem to be of high importance in throwing. More specifically, shoulder internal rotation, a functional elbow angle [9] as well as elbow extension [11] may play an important role in throwing velocity. Consequently, mobility in combination with segmental stability as assessed through the Upper Quarter Y Balance Test (YBT-UQ) may be of high importance for throwing proficiency development. The YBT-UQ has been shown to be a reliable and valid [17-19] closed chain test for the assessment of upper quarter mobility and stability. The YBT-UQ was performed by every subject demanding closed chain stability [17, 19-21] in all three reach directions tested, i.e. medial (MED), inferolateral (IL), and superolateral (SL).

At this time no studies have investigated adolescent Olympic handball players and their functional adaptation to a sport with a strong unilateral execution component in the upper extremities. The YBT-UQ assessment will be used as a possible test that could correlate with Olympic handball-specific performance measures and to further detect probable side differences. Thus, the primary purpose of the present study was to examine whether there are side differences between the throwing and non-throwing arm. A second aim was to assess the relationship between the YBT-UQ and Olympic handball-specific performance measures. These findings may help practitioners and scientists alike to assess the importance of training programs to decline dysfunctional asymmetries and to avoid decrements in throwing performance as the most important technique in Olympic handball. Additionally, the results may give insight into the demand to develop specific functional upper quarter mobility and stability programs in order to improve Olympic handball-specific throwing performance.

\section{Methods \\ Subjects}

All subjects $(n=14$ female aged 13 years, $n=24$ males aged 14 years, $n=18$ males aged 15 years) were Olympic handball players of a regional youth selection team of the Handball Association Niederrhein. The subjects were recruited due to their belonging to a regional youth selection team with a similar training regimen (i.e., training frequency of 3-4 times per week), playing level (i.e., regional) and age span (i.e. adolescence), also being comparable for both sexes. All subjects and their parents or legal guardians were informed about possible risks, the study's objectives, and testing procedure. Further, a video was send to their coaches 1 week before the testing to demonstrate the YBT-UQ. Written consent of all subjects and an informed consent of the parents or legal guardians was obtained prior to the testing. Exclusion criteria were any injury that prevented the subjects from training or playing in the 2 weeks prior to the testing as well as vestibular, visual or proprioceptive disorders and functional limitations that were judged as possibly affecting YBT-UQ or throwing performance. Prior to the first training participation of the selection team, all athletes had to complete a questionnaire about their medical and clinical status including any current medications. Besides the written consent and medical clearance to take part in the training of the team, every athlete had to present a mandatory cardiac screening for Olympic handball youth players, which was controlled for by the Olympic handball association. The study was carried out according to the declaration of Helsinki. Additional characteristics can be found in Table 1.

\section{Testing procedures \\ Measurements}

The testing was carried out on three different measurement days. All testings were executed at the same time in the evening in the training venue of the Olympic handball association. Testing personnel, which consisted of experienced raters, was identical for all three testings at every station. All subjects were randomly assigned to one of the three testing groups. All groups started at the same time with group 1 starting with the anthropometric assessment, group 2 starting with the YBT-UQ testing and group 3 starting with the throwing velocity and accuracy testing. Following each station, the groups were given a 5-min break to avoid fatiguing effects for the next station. A standardized verbal instruction was given prior to each test and a standardized warm-up was executed including $5 \mathrm{~min}$ of submaximal running followed 
Table 1 Characteristics of the study participants $(N=56)$ by group

\begin{tabular}{llll}
\hline Characteristic & F: 13 yrs. $(n=14)$ & M: 14 yrs. $(n=24)$ & M: 15 yrs. $(n=18)$ \\
\hline Body height $(\mathrm{cm})$ & $165.4 \pm 6.2$ & $178.3 \pm 7.6$ & $181.4 \pm 8.0$ \\
Body mass $(\mathrm{kg})$ & $58.9 \pm 12.2$ & $67.8 \pm 13.2$ & $69.8 \pm 10.1$ \\
Body mass index $\left(\mathrm{kg} / \mathrm{m}^{2}\right)$ & $21.4 \pm 3.5$ & $21.2 \pm 2.7$ & $21.2 \pm 2.4$ \\
Left arm length $(\mathrm{cm})$ & $83.4 \pm 4.3$ & $89.9 \pm 4.0$ & $92.7 \pm 4.1$ \\
Right arm length (cm) & $84.5 \pm 4.4$ & $90.6 \pm 4.1$ & $93.3 \pm 4.0$ \\
Arm dominance (L/R) & $1 / 13$ & $3 / 21$ & $3 / 15$ \\
Throwing arm (L/R) & $0 / 14$ & $2 / 22$ & $2 / 16$ \\
Training experience (yrs) & $5.9 \pm 1.3$ & $6.5 \pm 2.5$ & $9.3 \pm 2.2$ \\
\hline
\end{tabular}

Note. Values are mean \pm values standard deviations. $F$ Female; $L$ Left; $M$ Male; $R$ Right

by a mobility routine consisting of different functional exercises, and working with rubber bands as stretching was not permitted. Additionally, different standardized passing techniques (with Olympic handballs with the according throwing size 1 or 2 , depending on female or male subjects) were executed prior to the throwing attempts.

\section{Assessment of anthropometric characteristics}

Upper limb measurements were carried out with a tape measure from the seventh cervical spinous process to the distal tip of the middle finger of the arm with the shoulder in $90^{\circ}$ of abduction [22]. Measurement of body mass was assessed with a Seca clara 803 digital scale. Standing body height was assessed with a Seca linear measure scale without shoes. The subjects were asked to lean against the scale with their feet on the ground, looking forward and straight. The according height was determined in centimetres from the ground to the top of the subjects` head. Additionally, the subjects were asked for how many years they had been training and playing Olympic handball, which position they played and to identify their dominant and throwing arm.

\section{Assessment of upper quarter $Y$ balance test performance}

A Y Balance Test Kit (Move2Perform, Evansville, IN) was used together with an adapted YBT-UQ testing protocol. Standardized verbal instruction was given to all participants prior to executing the test and one of the experimenters performed a demonstration trial before the testing. All participants assumed a push-up position with their feet shoulder wide apart [22]. Out of this position, the participants moved the indicator with their free hand into the MED, IF, and SL directions (Fig. 1). All three reach directions had to be performed without any break and while maintaining the push-up position with the contralateral arm. The trial was stopped if the subject was either not maintaining the push-up position, dynamically pushing the indicator box out of his/her reach or lost three-point contact on the surface. After every complete trial, a 30-s rest period was granted before completing the next trial. When all three trials beginning with the right arm as the stance arm were completed, every subject performed the testing with the opposite limb with the same breaks as during the first trials. Each score was recorded for every reach direction and the best score was taken into consideration for the analysis [22]. The composite score (CS) was calculated as the mean of the averaged maximal distances in all three reach directions [23]. Additionally, all reaches were normalized for upper limb length.

\section{Assessment of throwing velocity and accuracy}

A target net (SG $500 \mathrm{~L}$; size: $3 \times 2 \mathrm{~m}$ ) was attached to a standard Olympic handball goal (Fig. 2). As scoring success is highly dependent on accuracy and velocity measures were taken of both. Previous studies [24-26] have found that there is a relationship between accuracy and velocity in Olympic handball throws and that an increase in velocity is not necessarily followed by a decrease in accuracy $[11,25,27]$ contrary to the speedaccuracy trade-off reported by other authors [28]. To measure throwing velocity a "Stalker Pro "radar gun (Applied Concepts Inc., 2609 Technology Drive, Plano, TX 75074-7467, USA) was used. The Doppler radar gun is reported to be a highly reliable instrument for the assessment of throwing velocity with an ICC between 0.97 and 0.98 [29]. The „Stalker Pro "is able to measure velocities from 0 to $480 \mathrm{~km} / \mathrm{h}$ with an accuracy of $0.16 \mathrm{~km} /$ $\mathrm{h}$ in a time interval of $0.01 \mathrm{~s}$. The working frequency is reported to be $35.1 \mathrm{GHz}$ with a low disturbance threshold. The radar gun was positioned $1.5 \mathrm{~m}$ behind the goal net in the height of $1.2 \mathrm{~m}$ in the direction of throwing to secure the Doppler effect and the right detection angle of throwing. To guarantee the correct assessment of the throwing velocity, a second radar gun was positioned behind the thrower. In case a value was not assessed by the first radar gun behind the goal net, the value of the second radar gun which was the same model, would 


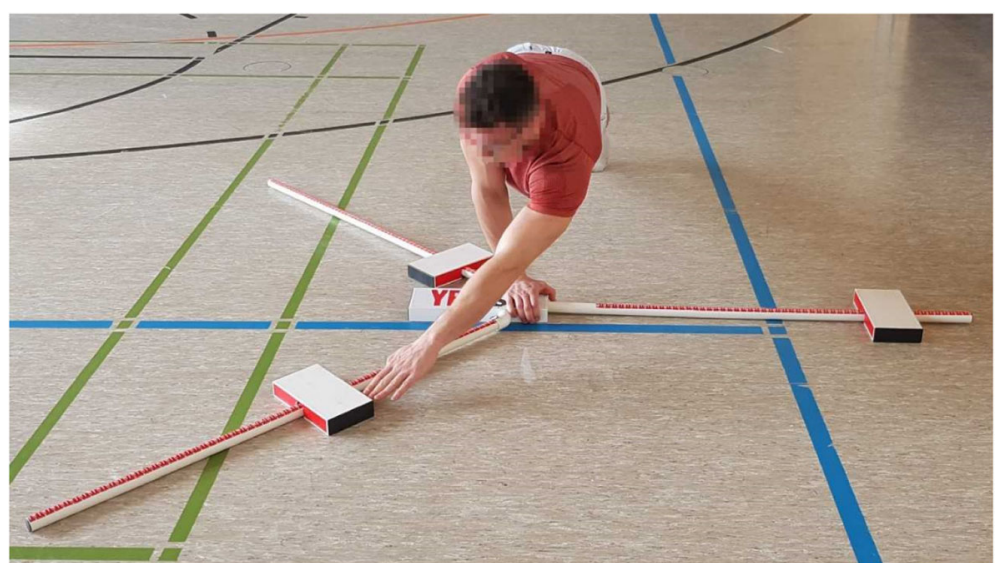

Fig. 1 Participant performing the YBT-UQ in superolateral reach direction

have been taken. One tester positioned himself behind the radar gun, while a second one was positioned behind the thrower with the second radar gun, with the third tester noting down the values into the scoring sheet.

Each subject stood with the contralateral foot in front of their throwing arm positioned at the $7-\mathrm{m}$ line. A bench was put alongside the 7-m line (Fig. 2). The contralateral foot was allowed to touch the bench, but the participants were not allowed to fall over the bench following the trial. The players had to use a throwing technique with the elbow at or above shoulder height. In case a player did not follow this requirement and threw under shoulder height, the trial had to be repeated. In line with the testing procedure of the German Handball Federation [30], the female athletes used a standard ball size 1 , while the male athletes used a standard ball size 2. The use of glue or resin was allowed to simulate a training or game-like situation as glue or resin is usually used during training or games on this competitive level. A standardized instruction was given prior to each task. As the first task, the subject had to throw the ball in the direction of the middle hole with maximal velocity. Each subject had three consecutive trials of which the one with the highest velocity was recorded. Between each trial, a short rest was permitted and the subjects executed the next throw based on their own perception of readiness. The test-retest reliability for the test of throwing velocity was reported to be $r=0.83$ [30]. As throwing and passing during games are primarily executed unilaterally with the dominant arm, only the throwing arm was tested. After all subjects executed the first task of throwing with the highest velocity possible, they were instructed to throw into the middle hole with the additional information that only the successful throws into the middle hole, i.e. accuracy was counted regardless of velocity with each successful throw being awarded one point. Again, every subject had three consecutive trials with a short rest to take the next ball after each trial, making it possible to achieve three points in total. For that task, every successful trial was counted by the testing personnel. All three raters observed if the throws were passing through the correct hole. As a third task,

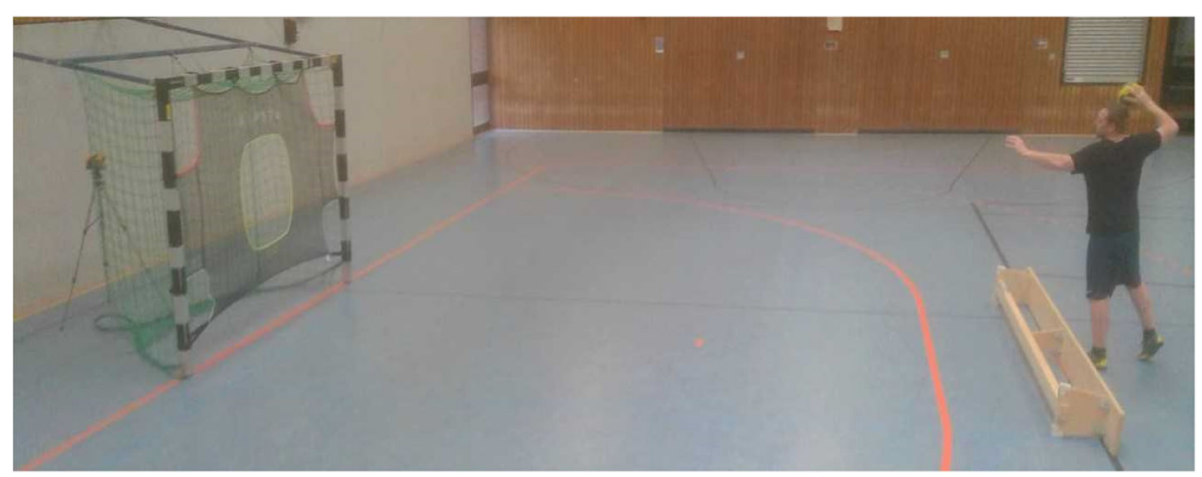

Fig. 2 Goal net with radar gun behind the posterior goal net 
the subjects had to throw into one of the four corners (Fig. 2). Every subject could decide for themselves which corner they used as a target and the same corner was allowed as a target for all three trials. As throws at the four corners have a lower scoring probability [31], it was decided to award successful throws at the centre with one point and successful throws at one of the corners with three points, making it possible to achieve nine points in total while velocity was not measured. The total score was calculated after the two tasks with the first one leading to $0-3$ points and the second one leading to $0-9$ points. Therefore, scoring of both scoring tasks together could lead to up to twelve points in total.

\section{Statistical analysis}

Descriptive statistics (i.e., means and standard deviations) were calculated for each group with SPSS version 24.0 (IBM Corporation, Armonk, NY, USA). Further, comparisons for YBT-UQ performance and throwing proficiency between the throwing and non-throwing arm were executed using paired $t$-tests. A $p$-value of $<0.05$ was considered statistically significant. In addition, Pearson's correlation coefficient $r$ was calculated for associations between YBT-UQ performance and throwing velocity. Based on the recommendations of Vincent [32], values of $0 \leq r \leq 0.69$ indicate small, $0.70 \leq$ $r \leq 0.89$ medium, and $r \geq 0.90$ large sizes of correlation.

\section{Results}

Table 2 illustrates mean values and standard deviations for the normalized YBT-UQ performance by group. We did not detect significant differences for any of the reach directions or the CS between the throwing and nonthrowing arm, except for the SL reach in the 14-year-old males (i.e., in favor of the non-throwing arm: $p=0.029$ ). YBT-UQ performance was greatest for the MED reach direction, followed by the IF and the SL reach directions.

Throwing performance is shown in Table 3. Based on the values of the German Handball Federation [30] which categorizes throwing velocities into the five categories, i.e., high above average, above average, average, below average, and highly below average - every individual group was ranked ( $\mathrm{F}=13$ yrs., $\mathrm{M}=14 \mathrm{yrs}$. and $\mathrm{M}=15 \mathrm{yrs}$ ) in the category "average".

Irrespective of group, the correlation analyses yielded solely small associations between YBT-UQ performance and throwing velocity/accuracy (13-year-old females: $0.01 \leq r \leq-0.37 \quad / \quad 0.01 \leq r \leq 0.31 ; 14$-year-old males: $0.10 \leq r \leq 0.45 / \quad-0.01 \leq \mathrm{r} \leq .-0.51 ; \quad 15$-year-old males: $0.06 \leq r \leq 0.34 / 0.01 \leq r \leq-0.45)$.

\section{Discussion}

The first purpose of this study was to assess whether there are side differences in UQ-YBT performance following the regular execution of a sport with a strong unilateral characteristic as given in Olympic handball. The second purpose was to determine whether a correlation exists between the UQ-YBT performance and the sport-specific measures (i.e. throwing accuracy and throwing velocity) of Olympic handball. The main results can be summarized as follows: (1) Overall, no consistent side differences could be detected for YBT-UQ performance of adolescent Olympic handball players in the present study. Side differences were only found in the 14-year-old male subjects; (2) Shoulder mobility/stability as assessed by the YBT-UQ did not predict shooting velocity and accuracy in adolescent Olympic handball players. The YBT-UQ was used due to its potential to expose asymmetries, which may lead to an increased risk of injury and functional decrements.

\section{Side differences in YBT-UQ performance}

Due to the mainly unilateral characteristic of Olympic handball and the regular sport-specific Olympic handball training process, it was expected that side differences existed between the throwing and the non-throwing arm. However, these side differences could not be confirmed in the present study. This finding goes in line with previous studies [34-36] on athletes performing a mainly unilateral sport. However, these studies mainly focused on high school and college baseball players, and sports in which less throws are performed with a ball with substantially less weight than an Olympic handball.

The side differences that were found in the 14-yearold male subjects in SL reach direction are a rather

Table 2 Upper Quarter Y Balance Test performance (\% arm length) by group

\begin{tabular}{|c|c|c|c|c|c|c|c|c|c|}
\hline Group & F: 13 yrs. $(n=14)$ & & & M: 14 yrs. $(n=24)$ & & & M: 15 yrs. $(n=18)$ & & \\
\hline$\overline{\text { Arm }}$ & T arm reach & NT arm reach & $p$-value & T arm reach & NT arm reach & $p$-value & T arm reach & NT arm reach & $p$-value \\
\hline MED & $111.8 \pm 10.0$ & $111.8 \pm 7.3$ & 1.000 & $112.4 \pm 7.6$ & $112.7 \pm 6.9$ & .805 & $111.2 \pm 10.6$ & $110.6 \pm 10.6$ & .739 \\
\hline IF & $98.9 \pm 11.0$ & $98.2 \pm 12.8$ & .842 & $108.8 \pm 12.1$ & $106.9 \pm 12.2$ & .379 & $106.0 \pm 10.6$ & $104.8 \pm 8.1$ & .555 \\
\hline$S L$ & $79.4 \pm 8.6$ & $78.1 \pm 7.3$ & .573 & $82.5 \pm 8.8$ & $79.9 \pm 9.4$ & .029 & $79.1 \pm 11.6$ & $80.0 \pm 10.0$ & .733 \\
\hline CS & $96.7 \pm 7.1$ & $96.1 \pm 7.5$ & .633 & $101.1 \pm 7.5$ & $99.7 \pm 7.1$ & .170 & $98.7 \pm 8.5$ & $98.3 \pm 7.3$ & .820 \\
\hline
\end{tabular}

Notes. According to Plisky [33] the arm that is being measured is the stance arm (i.e., T arm reach means that the NT arm is measured). Values are mean \pm values standard deviations. CS Composite score; IF Inferolateral; M Male; MED Medial; NT Non-throwing arm; F Female; SL Superolateral; $T$ Throwing arm 
Table 3 Throwing performance by group

\begin{tabular}{llll}
\hline Outcome & F: 13 yrs. $(n=14)$ & M: 14 yrs. $(n=24)$ & M: 15 yrs. $(n=18)$ \\
\hline Velocity $(\mathrm{km} / \mathrm{h})$ & $67.2 \pm 4.7$ & $85.9 \pm 7.4$ & $85.5 \pm 7.2$ \\
Accuracy $(\mathrm{pts}$ ) & $7.5 \pm 3.0$ & $5.0 \pm 3.1$ & $6.3 \pm 3.2$ \\
Velocity categorization & & & 0 \\
$\quad$ High above average & 0 & 0 & 4 \\
Above average & 3 & 8 & 12 \\
Average & 10 & 14 & 2 \\
Below average & 1 & 1 & 0 \\
Highly below average & 0 & 1 & 12 \\
\hline
\end{tabular}

Note. Values for velocity and accuracy are mean values \pm standard deviations. Values for velocity categorization are absolute numbers. $F$ Female; $M$ Male

surprising finding, given that no differences were found in either direction in the 13-year-old female and 15year-old male subjects. However, Wilson et al. [37] also reported a significant reach difference between the throwing arm and the non-throwing arm in SL reach direction in water polo players. Possibly, the better results of the non-throwing arm as the stance arm could be the result of its stabilising function and adaptation following throws with the throwing arm [37]. Therefore, the throwing arm may profit from a higher mobility whereas the non-throwing arm may adapt with greater stabilizing abilities following repetitive throws and passes. Additionally, the SL reach direction is the one most closely resembling the typical throwing movement [37]. Thus, it could be concluded that a significant functional adaptation in terms of asymmetries in the remaining directions does not occur possibly due to the overall training load for the adolescent Olympic handball players not being sufficient to lead to these adaptations.

\section{Associations between YBT-UQ and throwing performance}

Based on the present findings, shoulder mobility/stability as assessed by the YBT-UQ did not predict shooting velocity and accuracy in adolescent Olympic handball players. The finding that YBT-UQ and throwing performance solely showed small correlations goes in line with Štirn et al. [38] who reported a high number of factors contributing to the final ball velocity. Therefore, throwing was described as a highly multi-factorial skill, which cannot be predicted only based on the assessment of stability and mobility of the upper extremities [38]. Eriksrud [14] also reported no correlation between mobility and stability values as assessed through the hand reach star excursion balance test and throwing velocity in elite female Olympic handball players.

Olympic handball could be hypothesized as having an even stronger unilateral characteristic as other mainly unilaterally executed sports like basketball and soccer, due to the fact that passing and throwing are seldom executed with the non-throwing arm. Contrary to baseball or soccer, techniques in Olympic handball, which will also lead to functional adaptation [3] such as blocks, tackles in defence and any form of body contact are executed with both arms in equal distribution. This may be an explanation for the nonexisting differences between the throwing and nonthrowing arm. Olympic handball is therefore a sport with a mixture of closed and open chain actions. Probably, the rather low weight of the ball (ranging from 290 to $375 \mathrm{~g}$ for adolescents), albeit the high number of passes and throws, is not a sufficient stimulus to lead to significantly more pronounced strength and mobility adaptations of the throwing side.

Variations of the throwing technique with the elbow being shoulder height or higher may have led to different adaptations. Throwing velocity seems to be more important for backcourt players [39] who often have to throw from outside $9 \mathrm{~m}$ whereas accuracy seems to be more important for the wingers and pivots. A differentiation between playing positions could therefore be a valuable approach when assessing throwing velocity and accuracy. From a tactical point of view, it should also be kept in mind that fast executed throws in the game situation can be more important than high throwing velocities. The present study was executed from a central position, whereas several throws in the game are executed from different angles including the wings and only up to $10 \%$ of the throws in the game are standing throws with no run-up [15]. Therefore, future studies could also include jump throws, which are frequently displayed in training and games.

\section{Limitations}

There are a few limitations of this study that need to be outlined. First, as long as the requirement of the elbow being at least shoulder height during the throwing, variations of the throwing technique were possible. With this 
regimen, we followed the procedure of the German Handball Federation [30] in order to achieve comparable results. Second, the throwing was executed without contact of an opponent or the cognitive component of decision making which is always present in games, especially when goalkeepers and defenders have to be surpassed. Third, the present results can only be applied to standing throws and therefore the results cannot be transferred to the other throwing techniques, e.g., with a run-up or jump throws.

\section{Conclusions}

Olympic handball is a sport with a strong unilateral characteristic. The expected differences between the throwing and the non-throwing arm could not be confirmed in the present study. The lack of side differences leads to the possible consequence that the measurement of one side in all reach directions may be sufficient in determining stability and mobility of the upper extremities in adolescent Olympic handball players. Further and also against our assumption, YBT-UQ and throwing performance only showed a small predictive value. Therefore, alternative tests should be developed to predict throwing performances in adolescent Olympic handball players.

\section{Abbreviations}

pts.: Points; YBT-UQ: Upper quarter Y balance test; SL: Superolateral; MED: Medial; IF: Inferolateral; M: Male; F: Female; te: Training experience

\section{Acknowledgements}

The authors would like to thank the Olympic handball players who participated in this study and their coaches.

\section{Authors' contributions}

TM and JB designed the research question. JB planned and supervised the testings. JB, SS, and SF conducted the testings and data collection. TM and JB analysed the data. JB wrote the main part of the manuscript. TM, SS, and SF reviewed the manuscript. All authors approved the final manuscript.

\section{Funding}

We acknowledge support by the Open Access Publication Fund of the University of Duisburg-Essen. The funding body is independent of the design of the study and collection, analysis, and interpretation of data and in writing the manuscript.

\section{Availability of data and materials}

The data generated and analyzed during the present study are not publicly available due to ethical restrictions but are available from the corresponding author upon reasonable request.

\section{Ethics approval and consent to participate}

Ethical permission was given by the Human Ethics Committee at the University of Duisburg-Essen, Faculty of Educational Sciences. Before the start of the study, participants' assent and parents' written informed consent were obtained prior to the start of the study.

\section{Consent for publication}

Not applicable.

\section{Competing interests}

The authors declare that they have no competing interests. One of the authors, Professor Thomas Muehlbauer, PhD, is an Associate Editor of the BMC Sports Science, Medicine, and Rehabilitation journal.

Received: 5 March 2020 Accepted: 20 August 2020

Published online: 27 August 2020

\section{References}

1. Gorostiaga EM, Granados C, Ibanez J, Gonzalez-Badillo JJ, Izquierdo M. Effects of an entire season on physical fitness changes in elite male handball players. Med Sci Sports Exerc. 2006;38(2):357-66.

2. Loffing F, Hagemann N, Strauss B, MacMahon C. Laterality in sports. Amsterdam: Elsevier; 2016.

3. Paillard T. Plasticity of the postural function to sport and/or motor experience. Neurosci Biobehav Rev. 2017;72:129-52.

4. Muehlbauer T, Gollhofer A, Granacher U. Associations between measures of balance and lower-extremity muscle strength/power in healthy individuals across the lifespan: a systematic review and meta-analysis. Sports Med. 2015;45(12):1671-92.

5. Van den Tillaar R, Ettema G. Is there a proximal-to-distal sequence in overarm throwing in team handball? J Sports Sci. 2009;27(9):949-55.

6. Gorostiaga EM, Granados C, Ibanez J, Izquierdo M. Differences in physical fitness and throwing velocity among elite and amateur male handball players. Int J Sports Med. 2005;26(3):225-32.

7. Van den Tillaar R. Comparison of range of motion tests with throwing kinematics in elite team handball players. J Sports Sci. 2016;34(20):1976-82.

8. Debanne T, Laffaye G. Predicting the throwing velocity of the ball in handball with anthropometric variables and isotonic tests. J Sports Sci. 2011; 29(7):705-13.

9. Van den Tillaar R, Ettema G. A three-dimensional analysis of overarm throwing in experienced handball players. J Appl Biomech. 2007;23(1):12-9.

10. Fradet L, Botcazou M, Durocher C, Cretual A, Multon F, Prioux J, Delamarche P. Do handball throws always exhibit a proximal-to-distal segmental sequence? J Sports Sci. 2004;22(5):439-47.

11. Vila $H$, Ferragut $C$. Throwing speed in team handball: a systematic review. Int J Perf Anal Spor. 2019;19(5):724-36.

12. Wagner H, Pfusterschmied J, Von Duvillard SP, Muller E. Skill-dependent proximal-to-distal sequence in team-handball throwing. J Sports Sci. 2012; 30(1):21-9.

13. Serrien B, Baeyens J. Systematic review and meta-analysis on proximal-todistal sequencing in team handball: prospects for talent detection? J Hum Kinet. 2018;63(1):9-21.

14. Eriksrud O, Saeland F, Federolf $P$, Cabri J. Functional mobility and dynamic postural control predict overhead handball throwing performance in elite female team handball players. J Sports Sci Med. 2019;18(1):91-100.

15. Bencke J, van den Tillaar R, Møller M, Wagner $H$. Throwing biomechanics: aspects of throwing performance and shoulder injury risk. In: Laver $L$, Landreau P, Seil R, Popovic N, editors. Handball sports medicine: basic science, injury management and return to sport. Berlin: Springer; 2018. p. $69-80$.

16. Andersson SH, Bahr R, Clarsen B, Myklebust G. Preventing overuse shoulder injuries among throwing athletes: a cluster-randomised controlled trial in 660 elite handball players. Br J Sports Med. 2017;51(14):1073-80.

17. Westrick RB, Miller JM, Carow SD, Gerber JP. Exploration of the y-balance test for assessment of upper quarter closed kinetic chain performance. Int J Sports Phys Ther. 2012;7(2):139-47.

18. Schwiertz G, Brueckner D, Schedler S, Kiss R, Muehlbauer T. Reliability and minimal detectable change of the upper quarter $Y$ balance test in healthy adolescents aged 12 to 17 years. Int J Sports Phys Ther. 2019;14(6):927-34.

19. Gorman PP, Butler RJ, Plisky PJ, Kiesel KB. Upper quarter Y balance test: reliability and performance comparison between gender in active adults. J Strength Cond Res. 2012;26(11):3043-8.

20. Falsone SA, Gross MT, Guskiewicz KM, Schneider RA. One-arm hop test: reliability and effects of arm dominance. J Orthop Sports Phys Ther. 2002; 32(3):98-103.

21. Roush JR, Kitamura J, Waits MC. Reference values for the closed kinetic chain upper extremity stability test (CKCUEST) for collegiate baseball players. N Am J Sports Phys Ther. 2007;2(3):159-63.

22. Teyhen DS, Riebel MA, MCArthur DR, Savini M, Jones MJ, Goffar SL, Kiesel KB, Plisky PJ. Normative data and the influence of age and gender on power, 
balance, flexibility, and functional movement in healthy service members. Mil Med. 2014;179(4):413-20.

23. Borms D, Cools A. Upper-extremity functional performance tests: reference values for overhead athletes. Int I Sports Med. 2018;39(6):433-41.

24. Van den Tillaar R, Ettema G. Instructions emphasizing velocity, accuracy, or both in performance and kinematics of overarm throwing by experienced team handball players. Percept Mot Skills. 2003;97(3 Pt 1):731-42.

25. García JA, Sabido R, Barbado D, Moreno FJ. Analysis of the relation between throwing speed and throwing accuracy in team-handball according to instruction. Eur J Sport Sci. 2013;13(2):149-54.

26. Nuno A, Chirosa IJ, van den Tillaar R, Guisado R, Martin I, Martinez I, Chirosa $\sqcup$. Effects of fatigue on throwing performance in experienced team handball players. J Hum Kinet. 2016;54:103-13.

27. Van den Tillaar R, Ettema G. A comparison of overarm throwing with the dominant and nondominant arm in experienced team handball players. Percept Mot Skills. 2009;109(1):315-26.

28. Kawamura K, Shinya M, Kobayashi H, Obata H, Kuwata M, Hagio K, Nakazawa K. Development of Throwing Accuracy in Elementary School Handball Players. In: 34rd International Conference on Biomechanics in Sports: July 18-22 2016. Tsukuba: Konstanz; 2016.

29. Harasin D, Dizdar D, Markovic G. High reliability of tests of maximum throwing performance. J Hum Mov Stud. 2006;51 (1):63-76.

30. Deutscher Handballbund. Testmanual zur Leistungssportsichtung des DHB 2020. Dortmund/Leipzig: DHB/IAT; 2019.

31. Wagner $\mathrm{H}$, Finkenzeller $\mathrm{T}$, Wurth $\mathrm{S}$, von Duvillard SP. Individual and team performance in team-handball: a review. J Sports Sci Med. 2014; 13(4):808-16.

32. Vincent WJ. Statistics in kinesiology. Champaign, IL: Human Kinetics; 2005.

33. Plisky PJ. Y Balance Test Home Study Course. In: YBT Online Course. 2020. https://www.functionalmovement.com/articles/662/ybt_online-course/. Accessed 20 Jan 2020.

34. Butler RJ, Myers HS, Black D, Kiesel KB, Plisky PJ, Moorman CT, Queen RM. Bilateral differences in the upper quarter function of high school aged baseball and softball players. Int J Sports Phys Ther. 2014;9(4):518-24.

35. Myers $\mathrm{H}$, Poletti $\mathrm{M}$, Butler RJ. Difference in functional performance on the upper-quarter Y-balance test between high school baseball players and wrestlers. J Sport Rehabil. 2017;26(3):253-9.

36. Taylor JB, Wright AA, Smoliga JM, DePew JT, Hegedus EJ. Upper-extremity physical-performance tests in college athletes. J Sport Rehabil. 2016;25(2): $146-54$.

37. Wilson L, Leddington Wright S, Neza D. The assessment of arm dominance in water polo players using the Upper Quarter Y Balance Test. In: British Association of Sport and Exercise Sciences Annual Conference University of Central Lancashire: September, 2013. Lancashire: Preston; 2013.

38. Štirn I, Carruthers J, Šibila M, Pori P. Frequent immediate knowledge of results enhances the increase of throwing velocity in overarm handball performance. J Hum Kinet. 2017;56(1):197-205.

39. Rivilla-Garcia J, Grande I, Sampedro J, Van Den Tillaar R. Influence of opposition on ball velocity in the handball jump throw. J Sports Sci Med. 2011;10(3):534-9.

\section{Publisher's Note}

Springer Nature remains neutral with regard to jurisdictional claims in published maps and institutional affiliations.

\section{Ready to submit your research? Choose BMC and benefit from:}

- fast, convenient online submission

- thorough peer review by experienced researchers in your field

- rapid publication on acceptance

- support for research data, including large and complex data types

- gold Open Access which fosters wider collaboration and increased citations

- maximum visibility for your research: over $100 \mathrm{M}$ website views per year

At $\mathrm{BMC}$, research is always in progress.

Learn more biomedcentral.com/submissions 